\title{
Production of Xylella fastidiosa Diffusible Signal Factor in Transgenic Grape Causes Pathogen Confusion and Reduction in Severity of Pierce's Disease
}

\author{
Steven Lindow, ${ }^{1}$ Karyn Newman, ${ }^{1}$ Subhadeep Chatterjee, ${ }^{1}$ Clelia Baccari, ${ }^{1}$ Anthony T. lavarone,${ }^{2}$ and \\ Michael lonescu ${ }^{1}$ \\ ${ }^{1}$ Department of Plant and Microbial Biology, and ${ }^{2}$ QB3 Institute, University of California, Berkeley 97420, U.S.A.
}

Submitted 14 July 2013. Accepted 20 September 2013.

\begin{abstract}
The rpfF gene from Xylella fastidiosa, encoding the synthase for diffusible signal factor (DSF), was expressed in 'Freedom' grape to reduce the pathogen's growth and mobility within the plant. Symptoms in such plants were restricted to near the point of inoculation and incidence of disease was two- to fivefold lower than in the parental line. Both the longitudinal and lateral movement of $X$. fastidiosa in the xylem was also much lower. DSF was detected in both leaves and xylem sap of RpfF-expressing plants using biological sensors, and both 2-Z-tetradecenoic acid, previously identified as a component of $X$. fastidiosa DSF, and cis-11-methyl-2-dodecenoic acid were detected in xylem sap using electrospray ionization mass spectrometry. A higher proportion of $X$. fastidiosa cells adhered to xylem vessels of the RpfF-expressing line than parental 'Freedom' plants, reflecting a higher adhesiveness of the pathogen in the presence of DSF. Disease incidence in RpfFexpressing plants in field trials in which plants were either mechanically inoculated with $X$. fastidiosa or subjected to natural inoculation by sharpshooter vectors was two- to fourfold lower in than that of the parental line. The number of symptomatic leaves on infected shoots was reduced proportionally more than the incidence of infection, reflecting a decreased ability of $X$. fastidiosa to move within DSFproducing plants.
\end{abstract}

The xylem-limited bacterium Xylella fastidiosa causes Pierce's disease of grapevine as well as diseases of other important crop plants such as citrus, coffee, and almond (Chatterjee et al. 2008a; Hopkins and Purcell 2002). This pathogen moves extensively within plants after inoculation by xylem-feeding insects such as sharpshooter leafhoppers. The disease is progressive, occurring only weeks after inoculation, and is associated with blockage of an increasing proportion of xylem vessels by either bacterial cells themselves or tyloses produced by the plant in response to pathogen colonization of a given vessel (Baccari and Lindow 2011; Fry and Milholland 1990a and b; Purcell and Hopkins 1996; Sun et al. 2013). Most disease symptoms in plants colonized by $X$. fastidiosa such as leaf scorching can be explained by the progressive inability of the

Corresponding author: S. Lindow; E-mail: icelab@berkeley.edu

* The $\boldsymbol{e}$-Xtra logo stands for "electronic extra" and indicates that two supplementary figures are published online.

(C) 2014 The American Phytopathological Society plant to mobilize water to the upper parts of the plant as the incidence of vessel colonization increases (Purcell and Hopkins 1996; Sun et al. 2013). Thus, the ability of the pathogen to move between xylem vessels is associated directly or indirectly with symptom development.

$X$. fastidiosa exhibits a variety of context-dependent behaviors that enables both its efficient colonization of host plants and transmission by insect vectors. Most prominently, X. fastidiosa exhibits strong cell density-dependent patterns of gene expression that are mediated by the production and perception of an extracellular signal molecule known as diffusible signal factor (DSF) (Chatterjee et al. 2008a; Newman et al. 2004). DSF accumulates in populations of $X$. fastidiosa as cell numbers increase. 2-Z-tetradecenoic acid (XfDSF) is one of possibly several related DSF signal molecules produced by $X$. fastidiosa (Beaulieu et al. 2013). DSF production is conferred by the synthase RpfF and is perceived by RpfC, which then initiates a signal transduction cascade involving RpfG that ultimately results in alterations of the intracellular signal molecule cyclic-di-GMP (Chatterjee et al. 2008a, b, and c, 2010). At least 165 genes are downregulated in an $r p f F$ mutant compared with that of a wild-type strain while 281 are overexpressed (Wang et al. 2012). Several genes, including those encoding fimbrial and afimbrial adhesins, that would influence the virulence of $X$. fastidiosa are expressed more highly in the presence of DSF. In contrast, genes encoding type IV pili involved in twitching motility as well as those encoding extracellular enzymes such as polygalacturonases and endoglucanases are repressed in the presence of DSF (Wang et al. 2012). Although $r p f F$ mutants incapable of DSF production are hypervirulent to grape, they exhibit a very low efficiency of transmission by insect vectors compared with wild-type strains (Newman et al. 2004). The low transmissibility of $r p f F$ mutants was associated with their poor retention in vectors after feeding on infected plants; whereas large numbers of the wild-type strain colonized the mouth parts of sharpshooters, few cells of the rpfF mutant were retained (Newman et al. 2004). The phenotypes of an rpfF mutant seen in culture can account for both its hypervirulence and lack of its transmissibility; such mutants have a reduced ability to form biofilms and to adhere to surfaces while they exhibit enhanced twitching motility compared with the wild-type strain (Chatterjee et al. 2008c; de Souza et al. 2013). The hypervirulence of $r p f F$ mutants is apparently due to the fact that they colonize a larger proportion of xylem vessels in inoculated plants and grow to a higher population size in those vessels in which colonization has occurred compared with the wild-type strain (Chatterjee et al. 2008b). Excessive growth of $X$. fastidiosa within a given xylem vessel is also 
apparently deleterious, because most cells in those vessels that are heavily colonized are dead, as determined by propidium iodide staining (Chatterjee et al. 2008a). Therefore, it has been proposed that the accumulation of DSF by cells as they become numerous in a xylem vessel serves to suppress further growth (Chatterjee et al. 2008a).

Differential gene expression conferred by DSF accumulation has been proposed as a strategy used by $X$. fastidiosa to enable its successful colonization of xylem vessels while also enabling its transmission to new hosts by insect vectors, processes involving traits that would appear to be incompatible. In this model, given that most vessels of plants infected with $X$. fastidiosa harbor relatively small numbers of cells of this pathogen (Newman et al. 2003), local DSF concentrations within those vessels would be low. Thus, cells in most vessels would be capable of extracellular enzyme production and active motility but would lack expression of most cellular adhesins, thereby enabling them to move freely through the plant. In contrast, in those vessels in which cell numbers were larger, thus having correspondingly higher DSF concentrations, cells would exhibit the opposite phenotypes, thereby enabling them to be acquired by insect vectors. Thus, the population of cells of $X$. fastidiosa in a plant might be considered to be composed of two subpopulations representing active plant colonists and more sessile, transmissible forms.

Considerable circumstantial evidence suggests that the virulence of $X$. fastidiosa is low when its adhesiveness is high. $r p f C$ mutants which overproduce DSF in culture are hyperadhesive to surfaces, form more abundant biofilms, and are severely deficient in virulence to plants (Chatterjee et al. 2008c). The increased adhesiveness of this mutant apparently accounts for its much-reduced movement away from the point of inoculation in plants. Likewise, mutants of $\operatorname{cgs} A$, a gene that is downregulated in the presence of DSF which encodes a GGDEF protein capable of modulating intracellular concentrations of cyclic-di-GMP, are hyperadhesive and exhibited very low virulence to grape (Chatterjee et al. 2008c). We posit that the overproduction of DSF by $X$. fastidiosa would cause an increase in the proportion of cells that would be in the adhesive subpopulation, thereby reducing their ability to disperse within the plant. In such a scenario, a higher proportion of cells would have accumulated sufficient DSF to block their movement compared with wild-type cells. By such logic, we presume that, if DSF was omnipresent in plants, cells of $X$. fastidiosa would uniformly exhibit phenotypes inconsistent with their movement in plants and, thus, would remain localized near the point of inoculation. Although infection of such plants would not be prevented, the subsequent movement of the pathogen might be so restricted that symptom development would be averted. Although several strategies for elevating the levels of DSF in plants in the absence of the pathogen might be considered, in this report, we address the possibility of DSF production in transgenic plants harboring the DSF synthase of $X$. fastidiosa, RpfF. We show that DSF production occurs in transgenic grape and that $X$. fastidiosa exhibits greatly reduced mobility in such plants, leading to their greatly reduced susceptibility to Pierce's disease in both greenhouse and field trials.

\section{RESULTS}

Overproduction of DSF in $X$. fastidiosa reduces its virulence. Although the study of $r p f F$ and $r p f C$ mutants of $X$. fastidiosa had revealed an inverse relationship between the concentration of DSF produced and virulence in planta (Chatterjee et al. $2008 \mathrm{~b}$ and c), it was possible that these genes had influenced pathogenic behavior indirectly. To demonstrate the direct effects of elevated DSF levels on the virulence of $X$. fastidiosa, rpfF was expressed constitutively at a high level. The native $r p f F$ was replaced by one in which the kan promoter was fused $5^{\prime}$ to the structural gene. This strain produced substantially more DSF at a given assay time than did the wild-type strain (data not shown). The severity of disease in grape plants infected with this DSF-overproducing strain, as measured by the number of symptomatic leaves at a given time after inoculation, was much lower than that in plants inoculated with the wildtype strain (Supplementary Fig. S1). As expected, the severity of disease caused by an rpfF mutant was significantly higher than that of the wild-type strain at a given sampling time. Although the incidence of symptomatic leaves caused by both the wild-type and $r p f F$ mutant strains increased rapidly with time after approximately 80 days following inoculation, little temporal progression of disease was seen in plants infected with the $r p f F$ overexpressing strain; disease was restricted to sites close to the point of inoculation, and a maximum of only approximately two leaves per plant exhibited symptoms. Thus, the amount of DSF surrounding cells of $X$. fastidios $a$ appears to directly affect their virulence.

\section{Ectopic expression of $X$. fastidiosa DSF synthase in grape.}

To test whether an exogenous source of DSF could reduce the virulence of this pathogen, $r p f F$ from both $X$. fastidiosa and Xanthomonas campestris pv. campestris was expressed ectopically in 'Freedom' grape. 'Freedom' grape, which is susceptible to Pierce's disease, was chosen due to its ease of transformation. These similar $r p f F$ genes were expressed under the control of the Cauliflower mosaic virus (CaMV) 35S promoter. Transcripts of $r p f F$ were readily detected by reversetranscriptase polymerase chain reaction (RT-PCR) in each of nine transgenic lines generated (data not shown). All visual phenotypes of the $r p f F$-harboring plants were identical to that of the untransformed 'Freedom' parent. The disease susceptibility of these transformed lines following infection by Xylella fastidiosa was compared with that of the parental 'Freedom' by quantifying the number of leaves that showed scorching symptoms typical of Pierce's disease after mechanical inoculation of vines at their base with cell suspensions of the pathogen. Each of the transformed lines exhibited many fewer symptomatic leaves than the parental 'Freedom' line (hereafter referred to simply as 'Freedom') (Fig. 1). At 12 weeks after inoculation, 'Freedom' exhibited approximately eight symptomatic leaves per vine, whereas most $r p f F$-transformed lines exhibited fewer than two symptomatic leaves (Fig. 1). In all

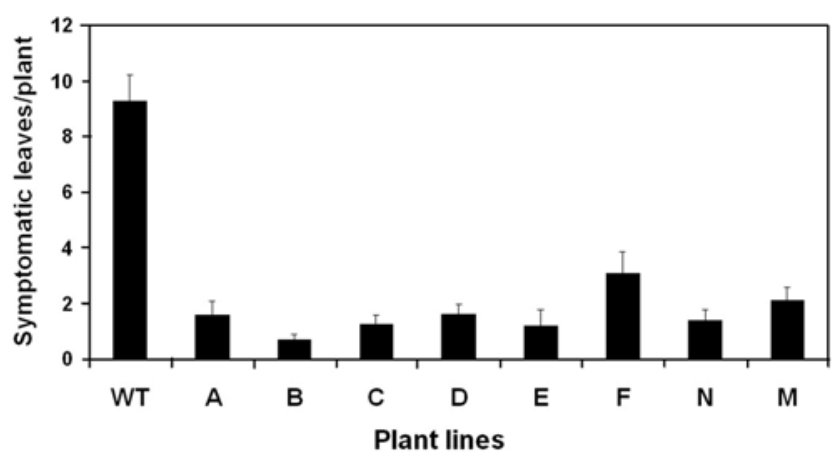

Fig. 1. Severity of Pierce's disease on greenhouse-grown wild-type 'Freedom' grape (WT) as well as in different transgenic lines transformed with the rpfF gene from Xylella fastidiosa (lines D, E, F, N, and M) or from Xanthomonas campestris pv. campestris (lines A, B, and C), as noted on the abscissa 12 weeks after inoculation with Xylella fastidiosa Temecula. Disease severity was quantified as the number of symptomatic leaves per plant. Vertical lines represent the standard error of the determination of mean disease severity. 
cases, symptomatic leaves in transgenic plants were located immediately adjacent to the point of inoculation. Disease incidence was similarly low in plants transformed with $r p f F$ from $X$. fastidiosa and from Xanthomonas campestris. Because the various transformed lines all exhibited similarly increased resistance to Pierce's disease in repeat experiments (data not shown), a single line harboring rpfF from Xylella fastidiosa (hereafter called FT2) was chosen for further evaluation.

The temporal dynamics of the appearance of symptomatic leaves of 'Freedom' and FT2 differed substantially. Typical of the slowly progressing nature of Pierce's disease, symptoms commenced 6 or 7 weeks following inoculation in both strains (Fig. 2). Thereafter, the incidence of symptomatic leaves increased much more rapidly in 'Freedom' than in FT2 (Fig. 2). Importantly, after 8 or 9 weeks, there was little further increase

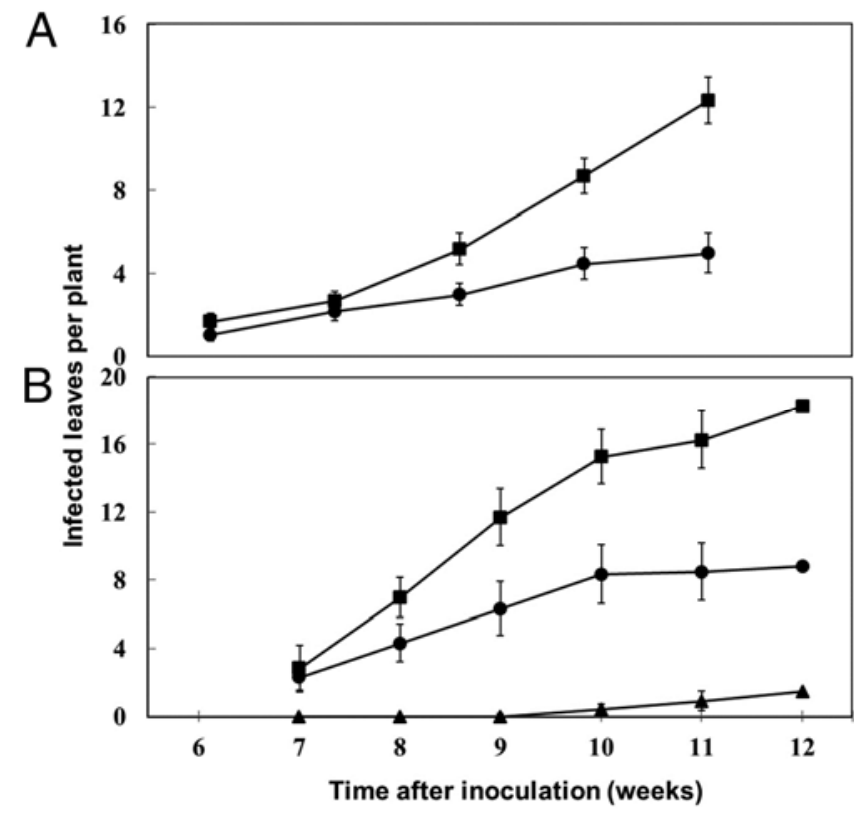

Fig. 2. Incidence of Pierce's disease symptoms in wild-type 'Freedom' grape (squares) and in transgenic line FT2 transformed with the $r p f F$ gene from Xylella fastidiosa (circles) at the various times after inoculation with $X$. fastidiosa shown on the abscissa. Also shown is the incidence of damaged leaves observed on uninoculated plants (triangles). A and B represent different repeats performed in the greenhouse. Vertical lines represent the standard error of the mean disease incidence at a given sampling time. in the incidence of symptomatic leaves in FT2, although symptomatic leaf incidence continued to increase in 'Freedom' (Fig. 2 ), causing the difference in disease severity between 'Freedom' and FT2 to increase with time. In each of several studies, symptomatic leaves on FT2 were only observed within approximately $30 \mathrm{~cm}$ of the point of inoculation, thereby affecting only approximately three (Fig. 2A) or five (Fig. 2B) leaves, depending on the internodal distance of plants in a given experiment. Thus, it appears that, although ectopic expression of rpfF in 'Freedom' grape does not prevent infection or symptom development, the spread of symptoms throughout the plant after inoculation is greatly restricted.

\section{Detection of DSF in transgenic lines expressing $r p f F$.}

The decreased symptom development in FT2 after inoculation with $X$. fastidiosa was associated with detectable amounts of DSF. DSF could be detected in intact leaves of FT2 using the Xanthomonas campestris pv. campestris-based DSF biosensor named $\mathrm{GC}^{\mathrm{ch}} \mathrm{F}$ ( $\triangle \mathrm{rpfCF}$ harboring Xylella fastidiosa RpfFG and an RpfC protein consisting of the transmembrane domain of $X$. fastidiosa $\mathrm{RpfC}$ and the cytoplasmic portion of Xanthomonas campestris RpfC), in which green fluorescent protein (GFP) fluorescence associated with a gfp:engA reporter gene fusion (Ionescu et al. 2013) was assessed. Intact leaves of either 'Freedom' or FT2 were surface sterilized and embedded in King's medium B agar (KB) medium over which another layer of KB was placed 3 days later. The GFP fluorescence exhibited by the $\mathrm{GC}^{\mathrm{ch}} \mathrm{F}$ biosensor after 3 days of growth on plates containing leaves of FT2 was significantly higher than that on plates containing 'Freedom' leaves which, in turn, was similar to that on control plates in which only methanol $(\mathrm{MeOH})$ was added (Fig. 3A). The GFP fluorescence of the biosensor on plates containing leaves of FT2 was similarly as high as that on control plates containing $10 \mu \mathrm{M} X f \mathrm{DSF}$, a DSF species produced by Xylella fastidiosa (Fig. 3A). Because X. fastidiosa is restricted to xylem vessels, we also assessed the apparent concentration of DSF in the xylem sap of grape to more directly relate the concentration of this signal molecule to the differential behavior of the pathogen in the plant. Xylem sap was expressed from healthy uninoculated plants of either 'Freedom' or FT2 using a pressure bomb. Cells of $X$. fastidiosa-based DSF biosensors consisting of a wild-type $X$. fastidiosa strain or $\mathrm{rpfF}^{*}$ mutant (harboring RpfF with substitutions of E141 and E161 to alanines) harboring a $h x f A: p h o A$ reporter gene fusion (XfHA) (Beaulieu et al. 2013; Ionescu et al. 2013) were incubated in xylem sap, and alkaline phosphatase activity,
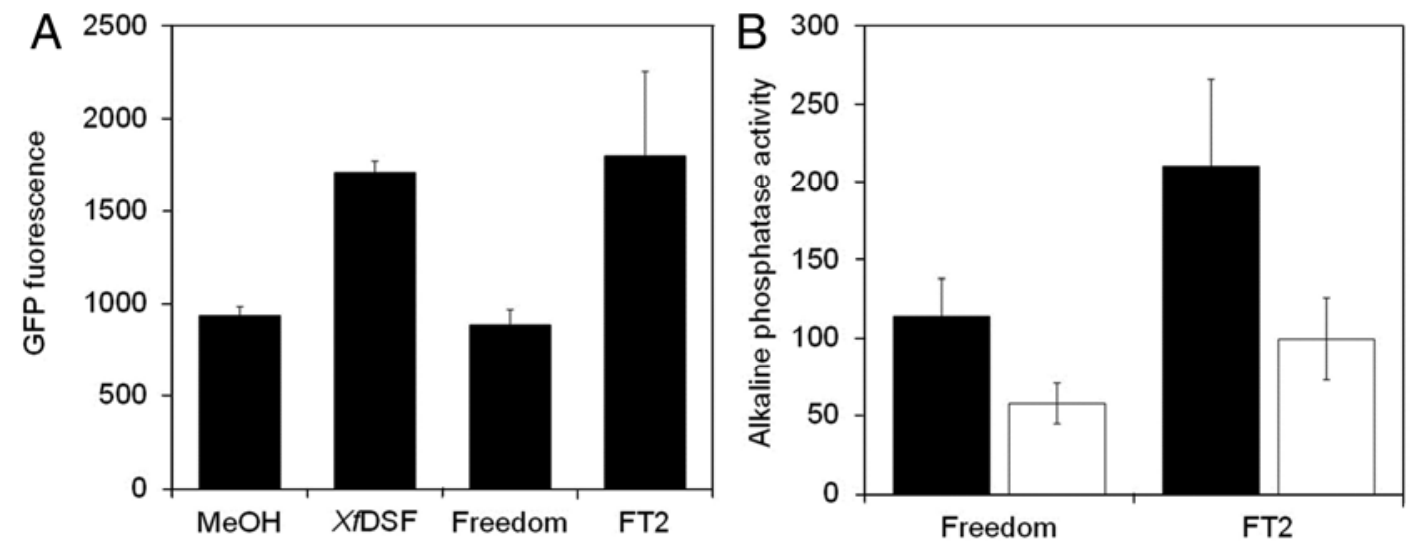

Fig. 3. A, Green fluorescent protein (GFP) fluorescence exhibited by Xanthomonas campestris-based GC $^{\text {ch }}$ F diffusible signal factor (DSF) biosensor cells recovered from colonies grown on agar plates in which leaves of wild-type (WT) 'Freedom' grape or transformed line FT2 harboring the rpfF gene from Xylella fastidiosa that had been embedded in the agar or on agar containing only methanol or 2-Z-tetradecenoic acid $(X f \mathrm{DSF})(10 \mu \mathrm{M})$. B, Alkaline phosphatase activity exhibited by cells of $X$. fastidiosa XfHA DSF biosensors (black bars, WT; white bars, $r p f F^{*}$ mutant; both harbor $h x f A^{\prime}:$ :phoA reporter gene fusion; incubation time of $72 \mathrm{~h}$ ) after suspension and xylem sap recovered from 'Freedom' grape or line FT2. Vertical lines represent the standard error of the mean. 
indicative of the presence of DSF, was assessed. At a given incubation time, the alkaline phosphatase activity of cells of $X f \mathrm{HA}$ incubated in xylem sap from FT2 plants was significantly greater than that of cells incubated in sap from 'Freedom' plants (Fig. 3B). Thus one or more DSF species to which $X$. fastidiosa is responsive could be detected in xylem sap of FT2 plants.

To identify the chemical species that accounted for DSF signaling activity in FT2, ethyl acetate (EtOAc) extracts of xylem sap collected from FT2 and 'Freedom' plants was subjected to electrospray ionization-mass spectrometry (ESI-MS). Importantly, a molecular species with an $\mathrm{m} / \mathrm{Z}$ ratio of 225.18 , corresponding to $X f \mathrm{DSF}$, was detected in xylem sap extracts from FT2 plants but not from 'Freedom' plants (Supplementary Fig. $\mathrm{S} 2$ ). Another molecular species with an $\mathrm{m} / \mathrm{Z}$ ratio of 253.22 was also found in xylem sap from FT2 but not from 'Freedom' plants. Such a mass would be consistent with that of $2-Z$ hexadecenoic acid, although the ability of this molecule to serve as a signaling molecule in $X$. fastidiosa has not been previously identified. Surprisingly, a molecular species with an $\mathrm{m} / \mathrm{Z}$ ratio of 211.17, consistent with that of DSF produced by Xanthomonas campestris pv. campestris, was detected in xylem sap from FT2 plants but not from 'Freedom'. Thus, several related 2-enoic acids appear to be produced in FT2 harboring the DSF synthase RpfF from Xylella fastidiosa. Although the presence of XfDSF and DSF, both previously demonstrated to mediate cell-to-cell signaling in X. fastidiosa (Beaulieu et al. 2013), can account for the signaling ability detected in xylem sap, other related molecular species with such signaling activity might also be present in FT2.

\section{Movement of $X$. fastidiosa in DSF-producing plants.}

Because $X$. fastidiosa can be present in plants that do not show symptom development, the growth and movement of a $g f p$-marked strain of $X$. fastidiosa was assessed in 'Freedom' and FT2 to better understand the processes that led to reduced symptom development in the rpfF-expressing plants. The population size of $X$. fastidiosa was similar (approximately $10^{6}$ cells/g) in stem segments taken within 60 to $90 \mathrm{~cm}$ of the point of inoculation 10 weeks after inoculation of both 'Freedom' and FT2 plants (Fig. 4). Importantly, whereas large population

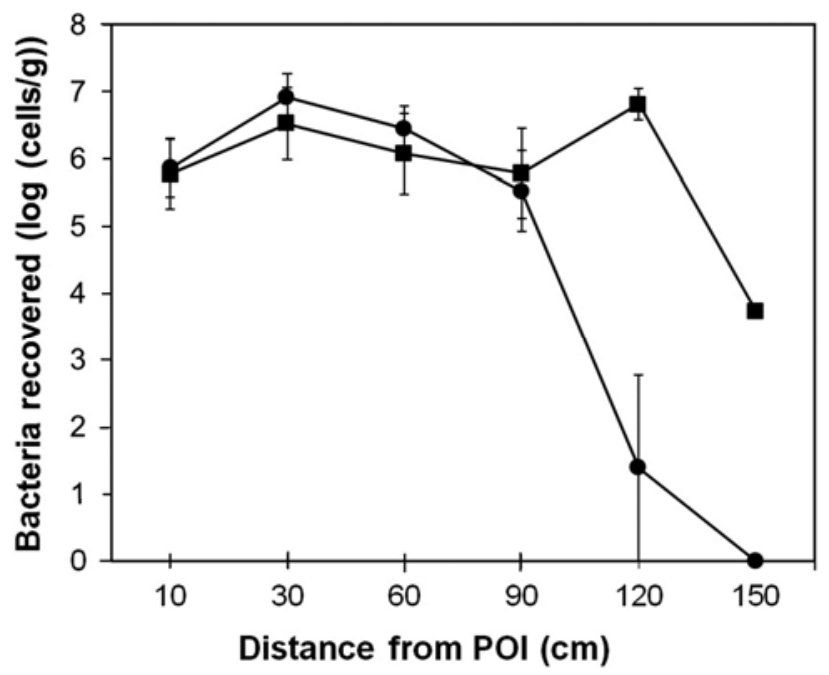

Fig. 4. Population size of wild-type Xylella fastidiosa in stems of 'Freedom' grape (squares) and a transgenic line FT2 harboring the rpfF gene from $X$. fastidiosa (circles) in stems segments taken at different distances from the point of inoculation (POI) 10 weeks after inoculation. Samples were collected from eight replicate plants for each treatment. Vertical bars represent the standard error of the mean. sizes of $X$. fastidiosa were recovered from 'Freedom' plants as much as $150 \mathrm{~cm}$ from the point of inoculation, the population size in FT2 plants at $120 \mathrm{~cm}$ from the point of inoculation were more than 10-fold lower than those in 'Freedom' and were undetectable at $150 \mathrm{~cm}$ (Fig. 4). The lateral movement of $X$. fastidiosa to xylem vessels at different distances from the point of inoculation was also assessed by determining the proportion of vessels in a stem that had any detectable GFPmarked cells as determined by fluorescence microscopy of stem cross-sections. The proportion of vessels of 'Freedom' that were colonized by the $g f p$-marked strain at a given distance from the point of inoculation was at least twofold higher than that in FT2 (Fig. 5). Whereas approximately 3\% of the vessels in stems of FT2 near the point of inoculation (10 cm distal) were colonized by at least some cells of $X$. fastidiosa, very few vessels were colonized at a distance of 60 $\mathrm{cm}$ and no vessels with colonization could be detected at a distance of $120 \mathrm{~cm}$ (Fig. 5). In contrast, at least $2 \%$ of the vessels of 'Freedom' harbored $X$. fastidiosa at a distance of $120 \mathrm{~cm}$ (Fig. 5). Thus, the longitudinal and lateral movement of $X$. fastidiosa in FT2 compared with 'Freedom' is greatly restricted.

\section{Adhesiveness of $X$. fastidiosa is elevated in DSF-producing plants.}

Given that DSF accumulation in $X$. fastidiosa was generally associated with the upregulation of genes that would contribute to its adhesiveness as well as with increased ability to form biofilms in vitro (Chatterjee et al. 2008a; Wang et al. 2012), we posited that the reduced movement of this pathogen through FT2 plants with elevated levels of DSF was due to its more tenacious binding to the plant. While assessing the spatial distribution of $g f p$-marked wild-type and $r p f F$ mutants of $X$. fastidiosa in grape, we observed that cells of the rpfF mutant were more readily released from the cut surfaces of infected stems than the wild-type strain. We reasoned that this was associated with their lower adhesiveness to xylem vessel surfaces as well as to themselves. Therefore, we tested whether a quantitative relationship existed between the escape of cells from severed stems and the apparent virulence of different strains. A "cell-release assay" was developed to quantify the relative adhesiveness of cells within plants. Segments $(5 \mathrm{~mm}$ in length) were cut from stems of surface-sterilized vines of plants infected with either a wild-type strain or $r p f F$ mutant,

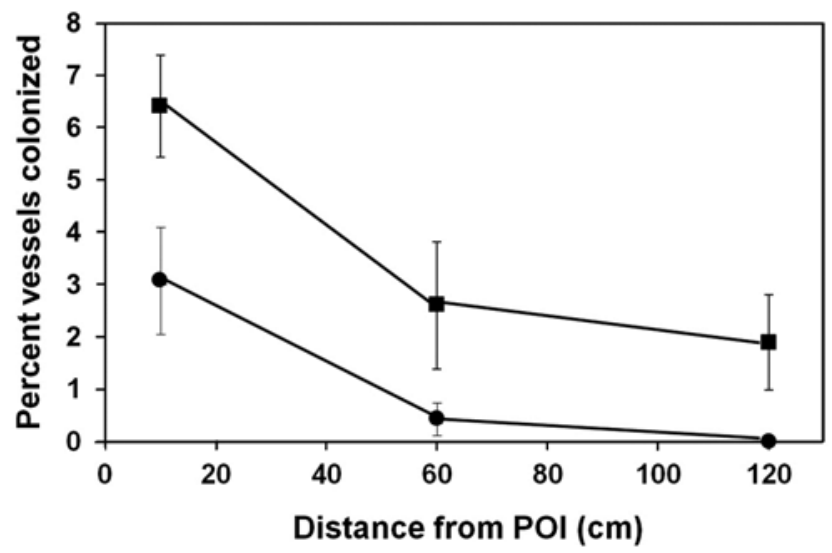

Fig. 5. Percentage of the total xylem vessels present in cross sections of stems of 'Freedom' grape (squares) or transgenic line FT2 (circles ) harboring the $r p f F$ gene from Xylella fastidiosa that harbored any cells of a green-fluorescent-protein-marked strain of $X$. fastidiosa when sampled at different distances from the point of inoculation (POI) 10 weeks following inoculation when examined by epifluorescence microscopy. Vertical lines represent the standard error of the mean. 
placed in sterile water, and gently agitated to allow the release of those cells that were not strongly attached to the plant. To normalize the numbers of cells that were released in this process for the number of cells available to be released, the remaining cells in the stem segments were enumerated after maceration. The proportion of cells released could then be calculated from the total number of cells present in the sample. The proportion of cells of an $r p f F$ mutant that were released was over threefold higher than that of the wild-type strain (Fig. 6). Whereas the proportion of cells of an $r p f G$ mutant that were released was also much higher than that of the wild-type strain, a lower percentage of cells of $r p f C$ and $\operatorname{cgs} A$ mutants which exhibited hyperadhesiveness in vitro (Chatterjee et al. 2008c, 2010) were released from stem segments (Fig. 6). The lower adhesiveness of the $r p f F$ mutant in this assay than the wild-type strain was associated with its higher virulence (Fig. 7). Importantly, a strong positive relationship between the proportion of cells of different $X$. fastidiosa strains released from plants in the cell-release assay and the severity of disease that they caused was observed (Fig. 7). Thus, the relative adhesiveness of $X$. fastidiosa strains to xylem vessels as revealed by this assay is strongly predictive of their virulence, presumably because movement ability within the plant is facilitated if cells do not adhere to plant surfaces.

Given the strong inverse relationship between the ability of cells to be retained in plants and their virulence, we assessed the retention of a wild-type strain of $X$. fastidiosa after inoculation into 'Freedom' and FT2 plants. When measured 80 days after inoculation in stem segments located $10 \mathrm{~cm}$ from the point of inoculation, a significantly lower fraction of cells was released from FT2 plants $(0.31 \pm 0.16)$ compared with wildtype plants $(0.83 \pm 0.11)$. Thus, cells of the wild-type $X$. fastidiosa strain appeared to be more adherent to the DSFproducing FT2 plants. We presume that the lesser ability of $X$. fastidiosa to move within FT2 and, thus, to cause symptoms compared with the parental 'Freedom' is associated with this hyperadhesiveness.

\section{Transmission of DSF}

from DSF-producing rootstocks into scions.

Given that $X$. fastidiosa is restricted to xylem vessels and that DSF species could be detected in xylem sap of FT2 plants harboring the DSF synthase RpfF (Fig. 3B), we reasoned that this signal molecule might be sufficiently mobile that its production in transgenic rootstocks could influence the behavior

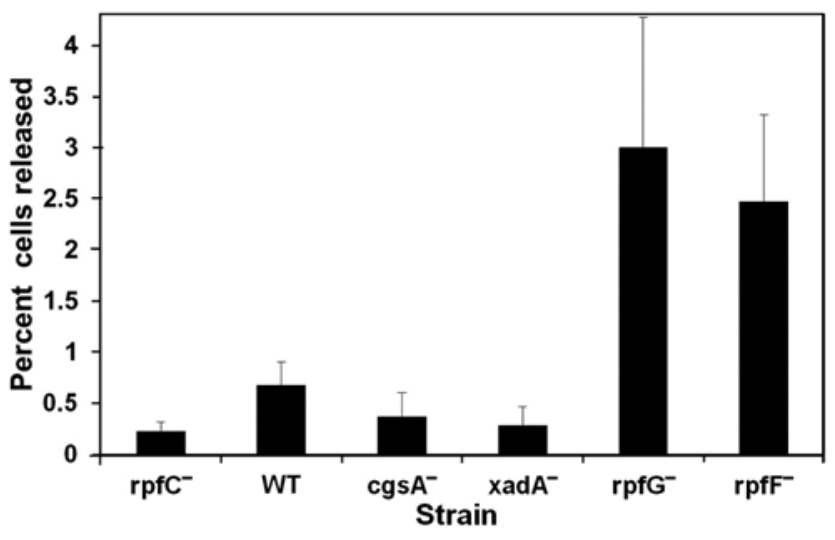

Fig. 6. Release of cells of different mutants of Xylella fastidiosa as well as a wild-type strain (WT) from the cut end of stems of 'Cabernet Sauvignon' grape 10 weeks after inoculation with a given strain. Shown is the percentage of the total cells present in a $5-\mathrm{mm}$ stem segment that were released during gentle agitation. Vertical lines represent the standard error of the determination of the mean. of the pathogen in nontransgenic scions. To test this conjecture, wild-type 'Cabernet Sauvignon' was grafted onto FT2 plants serving as a rootstock, and the incidence of Pierce's disease symptoms was assessed after mechanical inoculation of the scion with either of two wild-type $X$. fastidiosa strains. The number of symptomatic leaves on the 'Cabernet Sauvignon' scions grafted onto FT2 was approximately 30 and $20 \%$ lower than that on scions grafted onto 'Freedom' rootstocks when challenge inoculated with $X$. fastidiosa strains Temecula and STL, respectively (Fig. 8).

\section{DSF-producing grape more resistant}

to Pierce's disease in field trials.

To determine the robustness and environmental sensitivity of the control of Pierce's disease by elevated DSF levels in RpfFexpressing grape, we evaluated symptom development in FT2

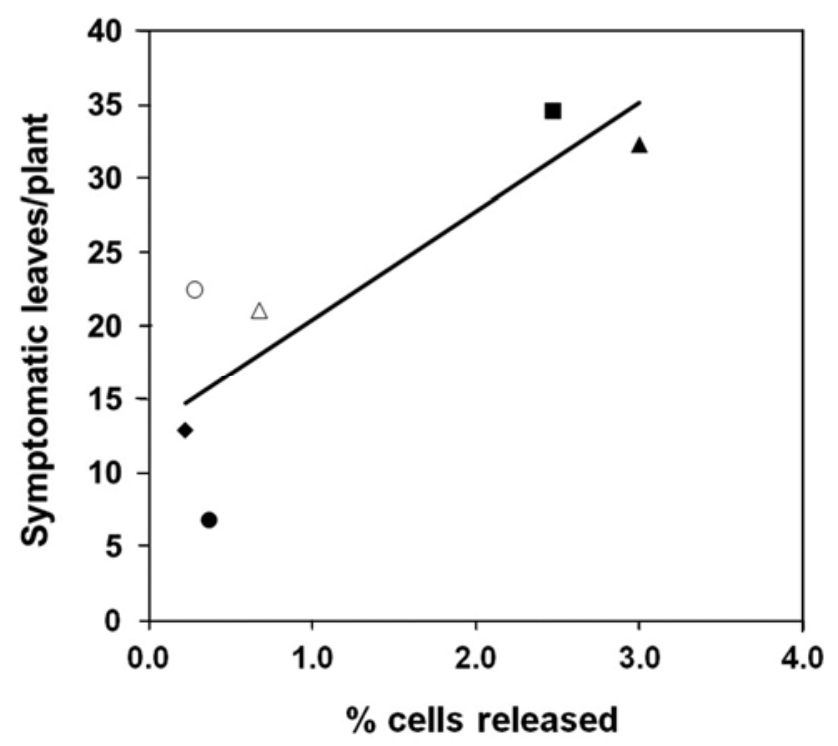

Fig. 7. Relationship between the adhesiveness of different mutant strains of Xylella fastidiosa as assessed by the percentage of cells released during gentle agitation of stem segments of 'Cabernet Sauvignon' plants infected by these strains and the virulence of the strains to 'Cabernet Sauvignon' grape measured as the number of symptomatic leaves per plant 12 weeks following inoculation with a given strain. Shown are results of studies of $\operatorname{cgs} A$ (filled circle), $r p f C$ (diamond), $x a d A$ (open circle), $r p f G$ (square), and $r p f F$ (filled triangle) mutants and wild-type strain Temecula (open triangle).

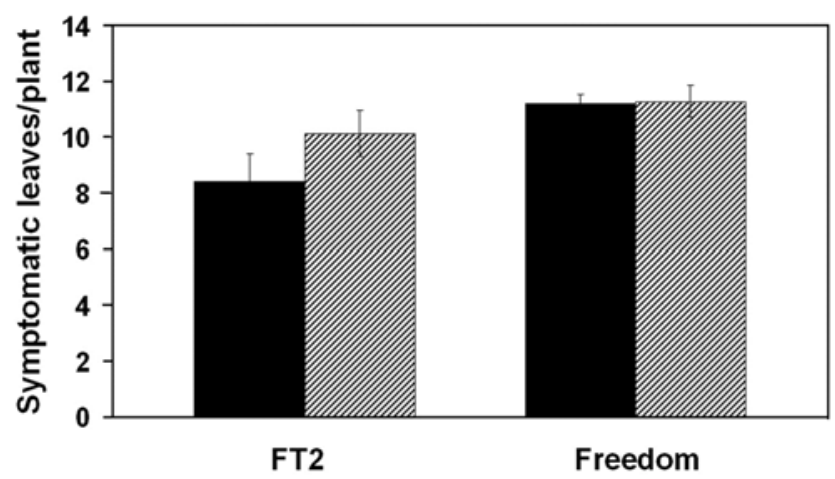

Fig. 8. Severity of Pierce's disease on 'Cabernet Sauvignon' grape grafted as scions onto either wild-type 'Freedom' grape or transgenic line FT2 harboring the $r p f F$ gene from Xylella fastidiosa 12 weeks after inoculation with $X$. fastidiosa strain Temecula (solid bars) or strain STL (striped bars). Plants were propagated in a greenhouse. Vertical lines represent the standard error of disease severity assessed as the number of symptomatic leaves per plant. 
and 'Freedom' after mechanical challenge inoculation in a northern California field trial and after natural infection due to glassy-winged sharpshooter (GWSS) (Homalodisca vitripennis) feeding in a Southern California field study. In addition, disease control conferred by DSF production in FT2 when serving as a rootstock onto which normal 'Thompson Seedless' grape was grafted as a scion was assessed in both trials. The incidence of infection of the inoculated, own-rooted FT2 plants at the northern California trial was reduced approximately three- and twofold in assessments made in August and September, respectively compared with 'Freedom' plants (Fig. 9 ). Disease was observed only near the point of inoculation in FT2 but had spread extensively in 'Freedom'. Because of the shading of inoculated vines by the vigorous growth of uninoculated vines of the same plant, many of the older leaves had died or fallen from the plant soon after Pierce's disease symptoms had appeared, especially by the September evaluation, making it difficult to quantify the number of infected leaves on a vine. When evaluated in August, however, 'Freedom' plants had approximately threefold more symptomatic leaves on each inoculated vine than did FT2 (Fig. 10). Likewise, the incidence

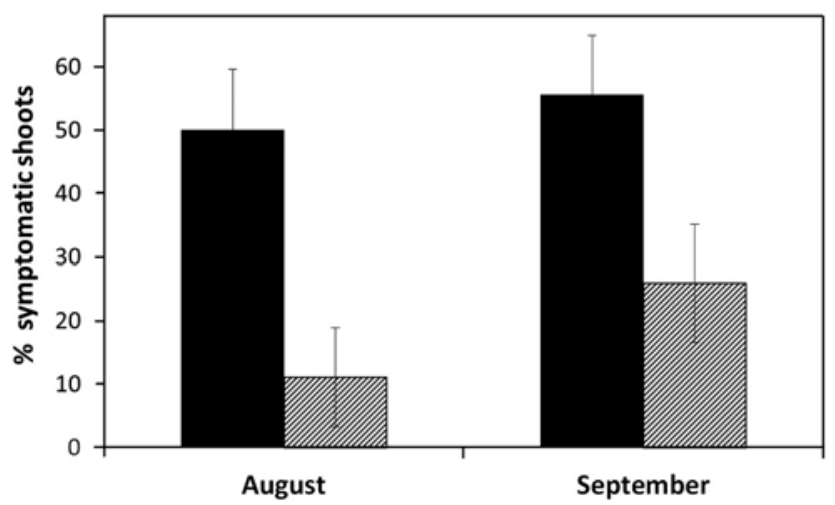

Fig. 9. Incidence of symptom development in inoculated shoots of parental 'Freedom' grape (solid bars) or transgenic line FT2 plants harboring the $r p f F$ gene from Xylella fastidiosa (striped bars) in a field trial in northern California when assessed in mid-August or mid-September following inoculation in mid-May with $X$. fastidiosa. Three randomly chosen shoots from the six shoots that had been inoculated were evaluated for each plant and disease incidences is shown as a percentage of the shoots that harbored leaves that exhibited any symptoms of Pierce's disease. Vertical lines represent the standard error of the mean.

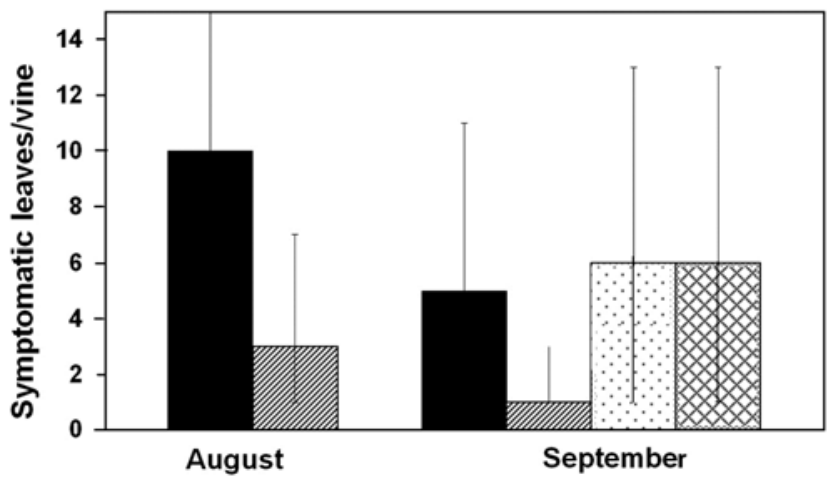

Fig. 10. Severity of Pierce's disease symptoms observed in mid-August or mid-September on vines of parental 'Freedom' grape (solid bars) or transgenic line FT2 plants harboring the $r p f F$ gene from Xylella fastidiosa (striped bars) inoculated in early May with $X$. fastidiosa in a northern California field trial. Also shown is the severity of disease on Thompson Seedless grape as a scion grafted on either 'Freedom' (dotted bar) or FT2 (hatched bar) rootstocks when assessed in September. Vertical lines represent the standard error of the mean disease severity assessed as the number of symptomatic leaves per inoculated vine. of symptomatic leaves was approximately fourfold higher on 'Freedom' plants than FT2 when assessed in September (Fig. 10). There was no difference in the number of leaves of Thompson Seedless grape grafted onto FT2 rootstocks that exhibited symptoms of Pierce's disease compared with that of scions grafted onto 'Freedom' rootstocks (Fig. 10). Thus, under field conditions, FT2 exhibited similarly reduced disease susceptibility as when tested in the greenhouse. However, no evidence was obtained for transmissibility of DSF from FT2 plants as rootstocks to scions.

The incidence of infection of 'Freedom' plants in the Southern California field trials subjected to natural inoculation by GWSS vectors was very high, with over $85 \%$ of the shoots on this highly branched variety exhibiting some leaf scorching typical of Pierce's disease when assessed in early October (Fig. 11). X. fastidiosa was recovered from the petioles of all symptomatic leaves tested, confirming that symptoms were due to Pierce's disease. Large numbers of GWSS detected in June and July 2012, approximately half of which harbored $X$. fastidiosa, were apparently responsible for the disease symptoms that subsequently appeared in September and October. Importantly, the incidence of infection of FT2 was approximately threefold less than that of 'Freedom', whereas the number of infected leaves per vine of FT2 was approximately fivefold less (Fig. 11). Although the frequency with which symptomatic leaves were observed on FT2 plants was much lower than on 'Freedom', the appearance of those leaves that were symptomatic was similar to that on 'Freedom' plants; all
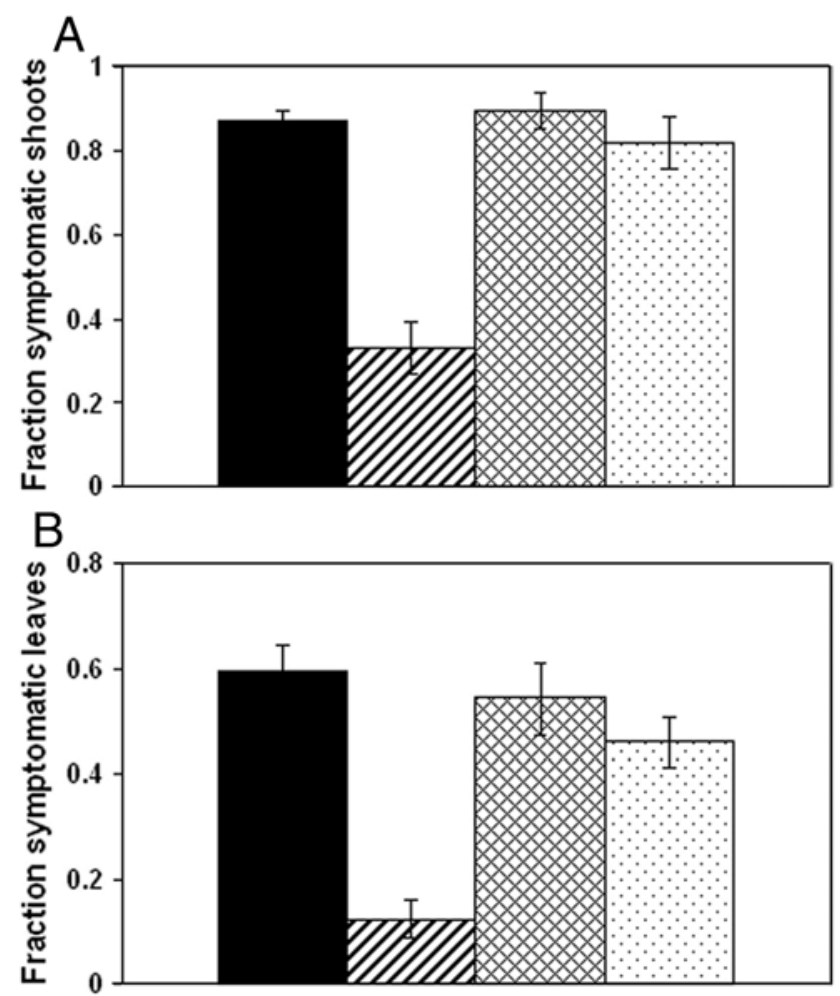

Fig. 11. A, Incidence of shoots of parental 'Freedom' grape (solid bars) or transgenic line FT2 harboring the rpfF gene from Xylella fastidiosa (striped bar) that exhibited any symptomatic leaves after natural infection with $X$. fastidiosa due to glassy-winged sharpshooter feeding in a Southern California field trial when assessed in early October. Also shown is the incidence of infection of Thompson Seedless grape grafted as a scion onto either 'Freedom' (hatched bars) or FT2 (dotted bars) rootstocks. B, Severity of infection of the plants as described above as measured by the fraction of the total leaves on a given shoot that exhibited symptoms of Pierce's disease. Vertical lines represent the standard error of the determination of the mean. 
symptomatic leaves exhibited marginal leaf scorching typical of Pierce's disease. The incidence of symptom occurrence on Thompson Seedless scions grafted onto 'Freedom' rootstocks was similar to that when grafted onto FT2 rootstocks (Fig. 11). Likewise, although numerically lower, the number of symptomatic leaves per Thompson Seedless vine grafted onto FT2 rootstocks was not significantly different than when grafted onto 'Freedom' (Fig. 11).

\section{DISCUSSION}

Expression of a nontargeted RpfF from both X. fastidiosa and $X$. campestris in 'Freedom' grape resulted in the production of sufficient concentrations of various $2-Z$-enoic acids that can serve as signaling molecules in X. fastidiosa to alter its behavior in these transgenic plants. The enzymatic activity of Bcam0581, a protein highly homologous to X. fastidiosa RpfF that mediates biosynthesis of cis-2-dodecenoic acid in Burkholderia cenocepacia, was recently shown to both catalyze the dehydration of 3-hydroxydodecanoyl-ACP to cis-2-dodecenoylACP and cleave the thioester bond to yield the corresponding free acid (Bi et al. 2012). We presume that $X$. fastidiosa $\mathrm{RpfF}$ also possesses these same features, although it probably shows a preference for longer-chain 3-hydroxyacyl-ACPs because the DSF species produced by of $X$. fastidiosa include XfDSF (Beaulieu et al. 2013). The process by which such a compound could be produced by the expression of RpfF in plants remains somewhat unclear. Plant fatty acid synthesis is not prominent within the cytosol and occurs primarily in the plastid, although some synthesis can also occur in the mitochondria (Ohlrogge and Jawarski 1997). However, plant tissues are capable of incorporating exogenously provided fatty acids into their endogenous lipids (Koo et al. 2005), indicating that fatty acids are mobile in the plant. The exogenous fatty acids can undergo different metabolic fates. Although the subcellular location of activation (attachment of $\mathrm{CoA}$ and $\mathrm{ACP}$ ) and elongation of exogenous fatty acids responsible for the metabolism of exogenous fatty acids are not known, pathways for chain elongation were observed to occur in microsomes (Barrett and Harwood 1998). Because microsomes, by definition, are vesicle-like artifacts derived from the endoplasmic reticulum (ER), it appears that pathways for chain elongation occur in the ER. Thus, RpfF might have access to activated fatty acids in the cytoplasm of transgenic plants.

In B. cenocepacia, it appears that BDSF synthesis results from a branch of the more classical fatty acid biosynthesis pathway by diverting 3-hydroxydodecanoyl-ACP (Bi et al. 2012). In plants, the majority of such corresponding acyl-ACP substrates for RpfF would be expected to be found within plastids, because a thioesterase is normally involved in converting such compounds to the free acid for release from the plastid. Thus, it is unclear whether there is sufficient 3-hydroxyacylACP of either plastid or mitochondrial origin in the cytoplasm of plants in which the nontargeted RpfF may predominantly reside to account for the DSF synthesis observed in these plants. Alternatively, the expression of $X$. fastidiosa rpfF in 'Freedom' grape may have allowed some transport of RpfF into the chloroplast. In any event, given that DSF species such as XfDSF are active as signaling agents in X. fastidiosa at concentrations as low as approximately $500 \mathrm{nM}$ (Beaulieu et al. 2013), RpfF synthase activity may not need to have been highly efficient to have enabled such low concentrations of DSF to have been produced. Given that both XfDSF and DSF were produced in grape harboring RpfF, we presume that the corresponding 3-hydroxyacyl-ACP substrates were available in 'Freedom' grape. It is possible, however, that different grape cultivars or plant species may differ in their ability to provide suitable substrates for RpfF. It seems likely that targeting RpfF to cellular compartments where the substrates for DSF synthesis may be more abundant could lead to enhanced production of this signal molecule. Clearly, further study of such heterologous fatty acid synthesis would aid in further efforts to achieve disease control by the pathogen confusion resulting from DSF production in plants.

It was fortuitous that the DSF species produced in transgenic plants harboring $X$. fastidiosa RpfF were sufficiently mobile that they could be found within xylem sap, because this pathogen is restricted to the xylem. Although we could not accurately estimate the concentration of DSF species in $x y-$ lem sap, especially because a family of related molecules appears to have been produced, they were found in sufficiently high concentration to induce expression of $h x f A$ in $X$. fastidiosa (Fig. 3) and, thus, were present in concentrations of at least $1 \mu \mathrm{M}$. The process by which such DSF molecules could transit from the living cells in which they are produced into the fluids in xylem sap is unknown. Because DSF is a passively released fatty acid (He and Zhang 2008; Ryan and Dow 2011), it seems likely that DSF produced in the plant cell can diffuse into the apoplast and to nearby xylem vessels. Xylem parenchymal cells are in close proximity to xylem vessels and might logically be the most obvious source of such molecules.

The production of DSF in RpfF-expressing grape appeared to reduce the incidence and severity of Pierce's disease by slowing the movement of the pathogen beyond the point of inoculation. Given that Pierce's disease is a progressive malady of grape that develops slowly after inoculation, the movement of $X$. fastidiosa through the plant appears to be the phenotype most linked to the disease process. The increasing proportion of vessels that are colonized by $X$. fastidiosa with time after inoculation is strongly descriptive of disease symptoms (Baccari and Lindow 2011; Fry and Milholland 2009a and b; Hopkins and Purcell 2002). The blockage of water flow is likely due not only to excessive growth of $X$. fastidiosa in some vessels but also to pathogen-induced tyloses of plant origin (Sun et al. 2013). Regardless of the method of blockage, extensive movement of the pathogen appears necessary for disease symptoms. Accumulation of DSF, while upregulating the expression of a variety of fimbrial and afimbrial adhesins, apparently suppresses active movement requiring both retractile type IV pili and extracellular enzymes (Chatterjee et al. 2008a; Wang et al. 2012). Although we could not assess the process of extracellular enzyme production or twitching motility in the transgenic plants, we could directly assess the apparent adhesiveness of cells to the plant. The cell-release assay proved to be a useful method to distinguish the relative ability of different genotypes of $X$. fastidiosa to adhere to the walls of xylem vessels (Figs. 6 and 7). Mutants of genes such as $r p f C$ and $\operatorname{cgs} A$, in which adhesins were overexpressed and which exhibit higher adhesiveness to abiotic surfaces (Chatterjee et al. 2008c, 2010), also were more strongly adherent to xylem vessels than the wildtype strain (Fig. 6). Importantly, the apparent increased adhesiveness exhibited by the wild-type strain in FT2 plants compared with 'Freedom' plants was of the same magnitude as that observed for the $r p f C$ and $\operatorname{cgs} A$ mutants compared with the wild-type strain in wild-type grape. Although reduced twitching activity and lower production of extracellular enzymes such as endoglucanase and polygalacturonase would also have been expected in FT2 plants, the reduced virulence of $X$. fastidiosa in FT2 plants may primarily be due to their reduced ability to move through the plant because of their increased adhesiveness.

The lack of a substantial effect of FT2 plants as a rootstock on symptom development of normal scions is likely due to the relative size of the source and sinks for DSF in such grafted 
plants. The FT2 rootstocks extended less than approximately $10 \mathrm{~cm}$ above the soil level. In contrast, scions grafted onto such rootstocks were over $1 \mathrm{~m}$ in length at the time of inoculation in greenhouse experiments, and were usually 2 to $3 \mathrm{~m}$ long by the time disease symptoms had appeared. It is noteworthy that, while a small decrease in apparent susceptibility of scions grafted onto FT2 rootstocks was observed in greenhouse studies, no such effect was seen in field studies. Thompson Seedless grape is a very robust variety, and its growth as a scion on FT2 plants in the field was much greater than in greenhouse studies. A much higher dilution of any DSF produced in the rootstock would have been expected in such scions. Even if the rate of DSF production in the FT2 rootstocks was as high on a per mass basis as when grown as an ownrooted plant, it would be expected that a very substantial dilution of the DSF would occur during its mobilization through the xylem vessels system. Unless present in very high concentrations in the FT2 rootstocks, the extensive dilution of DSF during transport to distal parts of the plant would likely reduce it to levels insufficient to alter pathogen behavior. Those sites in FT2 plants where maximal DSF production occurs remain unknown. DSF could be readily detected by biosensor strains in intact leaves embedded in agar (Fig. 3) but it remains unclear whether the leaves were the source or merely the sink of DSF produced elsewhere. If leaves are a major site at which DSF was produced, the lack of leaves on the FT2 rootstocks could also account for the absence of an effect on pathogen behavior in scions.

The reduced severity of Pierce's disease in both field trials was apparently due primarily to the reduced movement of $X$. fastidiosa after inoculation. Because plants were mechanically inoculated in the northern California trial, it was possible to directly assess the extent to which symptomatic leaves occurred distal to the point of inoculation. As was observed in greenhouse studies (Figs. 1 and 2), the number of symptomatic leaves on FT2 plants was much less than that on 'Freedom' plants (Fig. 10). Because plants were infected naturally by sharpshooter vectors in the southern California trial, the point of inoculation could not be determined. However, it is important to note that, while the proportion of shoots which had any detectable symptomatic leaves was reduced over twofold in FT2 compared with 'Freedom', the number of symptomatic leaves on a given shoot was reduced nearly fivefold (Fig. 11). Assuming that insect vectors fed on both FT2 and 'Freedom' plants equally, the lower incidence of disease in FT2 plants suggests that the restriction of movement of $X$. fastidiosa away from the point of inoculation was so severe that the pathogen did not enter even the leaf closest to the point of insect feeding. The larger reduction in disease severity than incidence of disease seen in both field trials is expected if the movement of the pathogen was reduced in the DSF-producing plants.

The higher resistance of DSF-producing grape to Pierce's disease can be explained by a scenario in which the pathogen prematurely adopts a suite of phenotypes that would restrict its ability to move in the plant. We presume that, in a wild-type plant, those small numbers of cells of $X$. fastidiosa introduced by sharpshooter feeding are free to move both within and between xylem vessels because their low local population sizes has not resulted in the production of sufficient DSF to upregulate adhesins or to downregulate type IV pili or extracellular enzymes. This appears to be the predominant situation in the plant because most vessels harbor relatively small numbers of cells of the pathogen (Newman et al. 2003). However, as colonization progresses, the population size of the pathogen in some vessels increases enough that the concentration of DSF would be sufficiently high for the phenotypic conversion of the cells to an adhesive form that could be acquired by insects but which would exhibit restricted growth and movement in the plant. In DSF-producing plants, we presume that most cells would experience sufficiently high DSF concentrations immediately after inoculation that the phenotypic conversion would be induced much earlier and more extensively.

Disease control by the process of pathogen confusion resulting from DSF production in plants probably differs mechanistically from that demonstrated by altering quorum sensing in other pathosystems. Because virulence traits in plant pathogens such as Pectobacterium sp. (Erwinia carotovora) are generally induced by the accumulation of quorum sensing signal molecules such as n-acyl homoserine lactones (AHLs), the reduced susceptibility of tobacco and potato harboring an AHL lactonase could be readily explained by a process of quorum quenching, whereby the AHL signal molecule produced by the pathogen was destroyed, preventing the induction of virulence factors (Dong et al. 2001). Alternatively, in some, but not all, plant species in which AHLs were produced, disease susceptibility can be reduced (Fray 2002; Mae et al. 2001; Toth et al. 2004). Apparently, in this strategy, the omnipresence of AHLs in some plants induces the premature expression of virulence factors by the pathogen which triggers early recognition by the host plant and, thus, a more successful host defense response. Given that $X$. fastidiosa lacks a type III secretion system, unlike other plant pathogens, its ability to interact with living host cells remains unclear. Although it is possible that induction of cell-to-cell signaling in $X$. fastidiosa by DSF in transgenic plants might also alter active interactions of this pathogen with its host, the most parsimonious explanation for the high resistance of DSF-producing plants to Pierce's disease is that the enhanced expression of adhesins and reduced expression of extracellular enzymes and retractile pili are sufficient to account for its reduced growth and movement in such plants. Although substantial reductions in susceptibility to Pierce's disease were seen in the DSF-producing plants studied here, further studies aimed at increasing the efficacy of this strategy to achieve disease control are warranted.

\section{MATERIALS AND METHODS}

\section{Bacterial strains used.}

Wild-type $X$. fastidiosa subsp. fastidiosa strains Temecula (Newman et al. 2003) and STL (Hill and Purcell 1995) as well as an rpfF mutant (KLN61) (Newman et al. 2004) and $g f p$ marked strain KLN59.3 (Newman et al. 2003) were used in this study; both strains were generated in strain Temecula. All wild-type strains were grown on periwinkle Gelrite (PWG) media (Hill and Purcell 1995) and strains KLN61 and KLN59.3 were grown on PWG containing kanamycin $(50 \mu \mathrm{l} / \mathrm{ml})$.

\section{Assessment of cell adhesion.}

The adhesiveness of cells of $X$. fastidiosa was assessed in a cell-release assay. The relative adhesiveness of different $X$. fastidiosa mutants was assessed 10 weeks following inoculation of 'Cabernet Sauvignon' plants with a given strain, as described above. Stem segments $(2.0 \mathrm{~cm}$ in length) were excised from the vine $10 \mathrm{~cm}$ distal to the point of inoculation. Stem segments were surface sterilized by submersion for $30 \mathrm{~min}$ in $0.5 \%$ sodium hypochlorite followed by $30 \mathrm{~min}$ in $80 \%$ ethanol. Surfacesterilized stem segments were then allowed to dry and a 5-mm segment was cut from the middle of the sample. The internal segment was then placed in $2 \mathrm{ml}$ of buffer in small plastic tubes and gently shaken $(150 \mathrm{rpm})$ for $20 \mathrm{~min}$ to release cells from the cut end of the segment. The segment was then removed from the washing solution and macerated with a mortar and pestle. The population size of $X$. fastidiosa was then determined by plating of appropriate dilutions of each fraction on 
PWG or on PWG containing kanamycin at $50 \mu \mathrm{g} / \mathrm{ml}$, as appropriate. The retention efficiency was calculated as the number of cells released during washing divided by the total number of cells present in the segment. At minimum, 15 replicate stem segments were assessed for each treatment. The retention efficiency of wild-type strain Temecula was determined 10 weeks after inoculation of 'Freedom' and FT2 by a similar procedure.

\section{Construction of $r p f F$-expressing transgenic grape.}

The $X$. fastidiosa rpfF gene was expressed from the $35 \mathrm{~S}$ rRNA promoter of CaMV. The CaMV-35S-rRNA promoter was obtained from the binary vector pCAMBIA1201 by digestion with HindIII and BglII. The segment carrying the promoter was gel purified and cloned into a different binary vector (pCAMPBRIA1390) through the HindIII and BamHI restriction sites to produce pKLN1. BglII and BamHI are isoschizomers. The $r p f F$ gene of $X$. fastidiosa was amplified from the $X$. fastidiosa Temecula genome using the primers listed in Table 1 . The forward primer $\left(X f_{-} r p f F-\mathrm{F} ; \mathrm{NcoI}\right)$ contains an NcoI restriction site while the reverse primer $\left(X f \_r f F-\mathrm{R} ; B a m \mathrm{HI}\right)$ contains a BamHI restriction site. The PCR product and pKLN1 were digested with $N c o$ I and either BamHI or $B g l \mathrm{II}$, respectively, and ligated to produce pKLN119 (35S-rRNA promoter::Xf_rpfF).

The rpfF gene of Xanthomonas campestris was amplified from the $X$. campestris pv. campestris 8004 genome by using the primers listed in Table 1 . The forward primer $\left(X c c \_r p f F-F\right.$; $B s p \mathrm{HI})$ contains a $B s p \mathrm{HI}$ restriction site while the reverse primer (Xcc_rpfF-R; $B g l \mathrm{II})$ contains a $B g l \mathrm{II}$ restriction site. The PCR product and pKLN1 were digested with $B s p \mathrm{HI}$ or $\mathrm{NcoI}$, respectively, and $B g l \mathrm{II}$ and ligated to produce pKLN124 (35SrRNA promoter::Xcc_rpfF). BspHI and NcoI are isoschizomers. The constructs were introduced by electroporation into Agrobacterium tumefaciens EHA 105 and transformation of 'Freedom' was conducted as in earlier studies (Aguero et al. 2005).

\section{Microscopy.}

Stem segments from plants inoculated with the GFP-marked Xylella fastidiosa strain were sectioned and prepared for microscopy by methods similar to those previously reported (Baccari and Lindow 2011; Newman et al. 2003). Individual hand-sectioned stem sections were mounted on a microscope slide and immersed in a $50 \%$ glycerol solution. Microscopic evaluation was done with $\times 5$ and $\times 10$ magnifications on an AxioImager373 Epifluorescence microscope. GFP fluorescence was captured using a filter optimized for use with fluorescein isothiocyanate (Deltavision) using a 490- to 528-nm band. Twelve sequential cross sections were prepared from tissues at a given distance from the point of inoculation immediately adjacent to each of the stem or petiole segments in which $X$. fastidiosa populations were determined by dilution plating of tissue macerates as in other studies (Baccari and Lindow 2011). The total number of vessels in a given cross section as well as the number of infested vessels was counted. The numbers of colonized vessels were averaged for each sampling location and normalized for the average number of total vessels per section. Multiple comparisons among treatment effects were made using a least significant difference test. All analyses were performed using Statistica (Statsoft Inc., Tulsa, OK, U.S.A.).

\section{MS of DSF in xylem sap.}

Entire vines of uninoculated, mature plants of 'Freedom' or FT2 were collected in September 2012 from the northern California field trial. Vines were cut into $40-\mathrm{cm}$ segments consisting of both stems and leaves and were placed in a pressure chamber with the basal end protruding and subjected to approximately 20 bar. Xylem sap $(20 \mathrm{ml})$ obtained from vines of 'Freedom' and FT2 plants was directly collected into a glass Erlenmeyer containing $30 \mathrm{ml}$ of EtOAc and mixed vigorously for $5 \mathrm{~min}$, and the EtOAc (now containing DSF) was separated from the aqueous phase with a separation funnel. The EtOAc was concentrated by evaporation using a Rotavapor R evaporator (Büchi, Flawil, Switzerland) and the dried residue was dissolved in $100 \mu \mathrm{l}$ of $\mathrm{MeOH}$. MS analysis of plant xylem sap extracts was performed using an LTQ Orbitrap XL mass spectrometer that was equipped with an ESI source (Thermo Fisher Scientific, Waltham, MA, U.S.A.). Mass spectra were recorded in the negative ion mode over the range $\mathrm{m} / \mathrm{z}=100$ to $500 \mathrm{using}$ the Orbitrap mass analyzer, in profile format, with a resolution setting of 100,000 (as measured at $\mathrm{m} / \mathrm{z}=400$ ). Mass spectra were processed using Xcalibur software (version 2.0.7 SP1; Thermo Fisher Scientific).

\section{Detection of DSF in plants.}

Four freshly excised young intact leaves were placed on the bottom of a $85-\mathrm{mm}$ petri dish and covered with $5 \mathrm{ml}$ of $\mathrm{MeOH}$ to sterilize their surfaces and to release DSF from the plant tissue. The $\mathrm{MeOH}$ was allowed to evaporate for $1 \mathrm{~h}$ in a hood. The leaves were then embedded in $5 \mathrm{ml}$ of $\mathrm{KB}$ (King et al. 1954) supplemented with kanamycin at $50 \mu \mathrm{g} / \mathrm{ml}$, natamycin at $20 \mu \mathrm{g} / \mathrm{ml}$, and benomyl at $12.5 \mu \mathrm{g} / \mathrm{ml}$ and the plates were incubated for 3 days at room temperature to allow diffusion of molecules into the medium. A fresh layer of $10 \mathrm{ml}$ of this medium was then overlaid on the initial layer. Inoculum of the Xanthomonas campestris-based $\mathrm{GC}^{\text {ch }} \mathrm{F}$ DSF-bioreporter (Ionescu et al. 2013) was grown for 3 days on KB supplemented with kanamycin at $50 \mu \mathrm{g} / \mathrm{ml}$, harvested with a loop, and suspended in sterile water to an optical density at $600 \mathrm{~nm}$ $\left(\mathrm{OD}_{600}\right)$ of 0.1 and several $10-\mu \mathrm{l}$ drops were applied to the

Table 1. Primers and plasmids utilized

\begin{tabular}{|c|c|c|}
\hline Primer, vector & Sequence or description & Use \\
\hline \multicolumn{3}{|l|}{ Primer } \\
\hline$X f \_r p f F-\mathrm{F}(N c o \mathrm{I})$ & TACCATGGCCGCTGTACATCCCATTCCTCACCCCATAT & $\begin{array}{l}\text { Cloning of Xylella fastidiosa rpfF gene into pKLN1 } \\
\text { to generate pKLN118 }\end{array}$ \\
\hline$X f \_r p f F-\mathrm{R}($ Bam HI) & CGGGATCCTCAGTTTTTTAGTGCTGTGTTTTTGTGAGTCT & \\
\hline$X c c \_r p f F-\mathrm{F}(B s p \mathrm{HI})$ & TGTCATGACTGCAGTTCAACCCTTCATTCGTACCAAT & $\begin{array}{l}\text { Cloning of Xanthomonas campestris rpfF gene into } \\
\text { pKLN1 to generate pKLN124 }\end{array}$ \\
\hline$X c c \_r p f F-\mathrm{R}(B g l \mathrm{II})$ & TGAAGATCTTCAGCCCGCGTCGAGCCCTGAGCGACGCGACT & \\
\hline $\mathrm{pC} 1390-\mathrm{R}$ & GGAAATTCGAGCTGGTCACCT & Verifying insertion of $r p f F$ into pKLN1 \\
\hline pKLN1-R & GATGTGCTGCAAGGCGATT & \\
\hline \multicolumn{3}{|l|}{ Vector } \\
\hline pCAMBIA1201 & cat (chloramphenicol-resistance gene), hptII (hygromycin-resistance gene) & Binary vector \\
\hline pCAMBIA 1390 & aadA (kanamycin-resistance gene), hptII & Binary vector \\
\hline pKLN1 & pCAMBIA1390 CaMV-35S-promoter::NOS-polyA & Binary vector \\
\hline pKLN118 & pKLN1 CaMV-35S-promoter::Xf_rpfF & Binary vector \\
\hline pKLN124 & pKLN1 CaMV-35S-promoter::Xcc_rpfF & Binary vector \\
\hline
\end{tabular}


plates at different locations. The plates were then incubated for 3 days at $28^{\circ} \mathrm{C}$ and cells from the spotted colonies collected with a sterile cotton swab and suspended in $5 \mathrm{ml}$ of $10 \mathrm{mM}$ phosphate buffer $\left(\mathrm{OD}_{600}=0.2\right.$ to 0.3$)$ in 13 -by-100-mm glass tubes. For each tube, relative fluorescence units (RFUs) were assessed using a TD-700 fluorometer, (Turner Designs, Holliston, MA, U.S.A.), $\mathrm{OD}_{600}$ was recorded using a Spectronics 21D Spectrophotometer (Milton Roy, Ivyland, PA, U.S.A.) and GFP fluorescence was normalized as RFU/OD 600 .

DSF in xylem sap was also assessed using a Xylella fastidi$o s a$-based biosensor. Inoculum of the $X$. fastidiosa wild-type or $r p f F^{*}$ mutant strain harboring plasmid pXfHA ( $\left.h x f A^{\prime}:: p h o A\right)$ were grown for 5 to 6 days at $28^{\circ} \mathrm{C}$ on PWG plates containing gentamicin at $10 \mu \mathrm{g} / \mathrm{ml}$ prior to suspension in Pierce's disease media \#3 (PD3) broth containing gentamicin at $20 \mu \mathrm{g} / \mathrm{ml}$ (final $\left.\mathrm{OD}_{600}=0.1\right)$. Cell suspension $(300 \mu \mathrm{l})$ in PD3 was then mixed in wells of a Falcon 48-well tissue culture plate (Becton Dickenson, Franklin Lakes, NJ, U.S.A.), with $300 \mu$ l of xylem sap expressed from either 'Freedom' or FT2 plants collected as described above, but was not subjected to EtOAc extraction. The alkaline phosphatase activity of the cultures in the wells was determined after $72 \mathrm{~h}$ of incubation. The plate was centrifuged for $10 \mathrm{~min}$ at 2,254 $\times \mathrm{g}$ in an Eppendorf model 5804 centrifuge (Eppendorf, Hamburg, Germany), the growth medium was removed by aspiration, and the cells were resuspended in 0.4 $\mathrm{ml}$ of $10 \mathrm{mM}$ Tris-Base ( $\mathrm{pH}$ 8.0) containing $10 \mathrm{mM} \mathrm{MgSO}_{4}$. The cells were pelleted again by centrifuging for $10 \mathrm{~min}$ at $2,254 \times g$, resuspended in $0.4 \mathrm{ml}$ of $1 \mathrm{M}$ Tris-Base $(\mathrm{pH} \mathrm{8.0)}$ containing $0.4 \mathrm{mM} \mathrm{ZnCl}$, and the cell density $\left(\mathrm{OD}_{600}\right)$ in each well was measured. The cells were then disrupted by adding $7 \mu \mathrm{l}$ of $0.1 \%$ sodium dodecyl sulfate and $7 \mu \mathrm{l}$ of chloroform to each well followed by $5 \mathrm{~min}$ of shaking $(200 \mathrm{rpm})$ at room temperature. Then, $60 \mu \mathrm{l}$ of $1 \mathrm{M}$ Tris-Base ( $\mathrm{pH}$ 8.0) containing $0.4 \mathrm{mM} \mathrm{ZnCl}_{2}$ supplemented with $100 \mu \mathrm{M}$ fluorescein diphosphate (Anaspec, Fremont, CA, U.S.A.) was added to each well and fluorescence (excitation, $485 \mathrm{~nm}$; emission, $515 \mathrm{~nm}$ ) and $\mathrm{OD}_{600}$ were measured at 2-min intervals for $30 \mathrm{~min}$ using a Synergy 2 plate reader (Biotek, Winooski, VT, U.S.A.). Enzyme activity was calculated as the rate of increase of fluorescence with time divided by the cell density.

\section{Greenhouse measurement of disease susceptibility.}

Plants of 'Freedom' grapevine, (Vitis champinii $\times($ V. solonis $\times$ $V$. othello)) or FT2 were grown in a greenhouse to a height of approximately $50 \mathrm{~cm}$ and mechanically inoculated with $X$. fastidiosa Temecula using a droplet puncture method as described before (Hill and Purcell 1995). Plants were trained to have only one stem per plant. Inoculum consisted of 5 - $\mu 1$ droplets of a given cell suspension $\left(10^{8} \mathrm{cells} / \mathrm{ml}\right)$. Plants were grown in the greenhouse for at least 10 weeks after inoculation, until initial symptoms of Pierce's disease appeared. The abundance of $X$. fastidiosa was then assessed by dilution plating of stem macerates on PWG with and without kanamycin, as appropriate (Hill and Purcell 1995). Disease severity was assessed as the number of leaves on each inoculated vine exhibiting leaf scorching symptoms typical of Pierce's disease as before (Newman et al. 2004). All vines were of a similar length and harbored similar numbers of leaves at a given time of assessment. In some studies, Thompson Seedless grape ( $V$. vinifera) was grafted onto either 'Freedom' or FT2 plants used as a rootstock. A "V" notch was cut on the distal end of vine segments (approximately $20 \mathrm{~cm}$ in length, with a diameter of approximately $1 \mathrm{~cm}$ ) containing one internode of these varieties. The basal end of a Thompson Seedless grape stem segment of the same diameter and approximately $20 \mathrm{~cm}$ long was mated to the rootstock segment and the junction wrapped with parafilm. The base of the joined segments was then embedded in a bed of vermiculite inside a mist tent held at $25^{\circ} \mathrm{C}$ and incubated for approximately 30 days to initiating root development on the rootstock. Plants were then propagated and inoculated as before.

\section{Field assessment of disease susceptibility.}

Field trials of 'Freedom' and FT2 grown as own-rooted plants as well as serving as rootstocks for plants with Thompson Seedless as a scion were established at experimental farms located near Davis, CA and Riverside, CA. Own-rooted plants were established from green stem segments rooted as above. Plants (approximately $80 \mathrm{~cm}$ tall) at the northern California trails were planted in August 2010 while the southern California trial was planted in April 2011. Each site consisted of a randomized complete block design with three adjacent plants of a given genotype established in each of four replicate blocks (rows). Plants were planted approximately $2.5 \mathrm{~m}$ apart in rows separated by approximately $2.5 \mathrm{~m}$. Plants in the northern California trial were inoculated (six vines per plant) with $X$. fastidiosa (approximately $10^{8}$ cells $/ \mathrm{ml}$ ) using a droplet puncture method as above because little natural inoculum of this pathogen occurs in this area. Plants in the southern California trial were subjected to natural infection due to the presence of GWSS vectors harboring $X$. fastidiosa. Large numbers of GWSS (as many as 60 insects per trap) were detected beginning as early as 1 June 2012, peaking in mid-July, but remaining abundant through mid-September. A relatively large proportion of these insects (approximately 55\%) harbored X. fastidiosa in midJuly, accounting for the relatively high incidence of infection that occurred in in this plot area.

The severity of disease in the northern California plot was assessed by counting the number of leaves exhibiting scorching symptoms or which had fallen from vines distal to the point of inoculation which had been marked with a plastic tie. Because the insect inoculation site was unknown for plants in the southern California site, the total number of leaves as well as the number of symptomatic leaves were assessed for each of the many discrete vines on a given plant (average of approximately 30 vines/plant for 'Freedom' and FT2 and approximately six vines for Thompson Seedless scions).

\section{ACKNOWLEDGMENTS}

We thank D. Gilchrist and T. Miller for assistance and coordination of field plots in Northern and Southern California, respectively; C. Sanscartier for her measurements of GWSS in the southern California field plot; R. Koutsoukis for greenhouse plant propagation and disease assessment; K. Yokota for assistance in measuring disease severity in field studies; D. Tricoli and the staff of the Ralph M. Parsons Foundation Plant Transformation Facility at the University of California, Davis for performing the transformation of grape; and B. Rotz for her assistance in greenhouse plant propagation.

\section{LITERATURE CITED}

Aguero, C. B., Uratsu, S. L. Greve, C., Powell, A. L. T., Labavitch, J. M., Meridith, C. P., and Dandekar, A. M. 2005. Evaluation of tolerance to Pierce's disease and Botrytis in transgenic plants of Vitis vinifera L. expressing the pear PGIP gene. Mol. Plant Pathol. 6:43-51.

Baccari, C., and Lindow, S. E. 2011. Assessment of the process of movement of Xylella fastidiosa within susceptible and resistant grape varieties. Phytopathology 101:77-84.

Barrett, P. B., and Harwood, J. L. 1998. Characterization of fatty acid elongase enzymes from germinating pear seeds. Phytochemistry 48:1295-1304.

Beaulieu, E., Ionescu, M., Chatterjee, S., Yokota, K., Trauner, D., and Lindow, S. E. 2013. Characterization of a diffusible signaling factor from Xylella fastidiosa. mBio 4. doi:10.1128/mBio.00539-12. Published online.

Bi, H., Christensen, Q. H., Feng, Y., Wang, H., and Cronan, J. E. 2012. The Burkholderia cenocepacia BDSF quorum sensing fatty acid is synthesized by a bifunctional crotonase homologue having both dehy- 
dratase and thioesterase activities. Mol. Microbiol. 83:840-855.

Chatterjee, S., Almeida, R. P. P., and Lindow, S. E. 2008a. Living in two worlds: The plant and insect lifestyles of Xylella fastidosa. Annu. Rev. Phytopathol. 46:243-271.

Chatterjee, S., Newman, K. L., and Lindow, S. E. 2008b. Cell-cell signaling in Xylella fastidiosa suppresses movement and xylem vessel colonization in grape. Mol. Plant-Microbe Interact. 21:1309-1315.

Chatterjee, S., Wistrom, C., and Lindow, S. E. 2008c. A cell-cell signaling sensor is required for virulence and insect transmission of Xylella fastidiosa. Proc. Natl. Acad. Sci. U.S.A. 105:2670-2675.

Chatterjee, S., Killiny, N., Almeida, R. P. P., and Lindow, S. E. 2010. Role of cyclic diGMP in Xylella fastidiosa biofilm formation, plant virulence and insect transmission. Mol. Plant-Microbe Interact. 23:1356-1363.

de Souza, A. A., Ionescu, M., Baccari, C., da Silva, A. M., and Lindow, S. E. 2013. Overlap in phenotypes controlled by the cyclic di-GMP phosphodiesterase EalXF in response to antibiotic exposure and DSF-mediated cell-cell signaling in Xylella fastidiosa. Appl. Environ. Microbiol. 79:3444-3454.

Dong, Y. H., Wang, L. H., Xu, J. L., Zhang, H. B., Zhang, X. F., and Zhang, L-.H. 2001. Quenching quorum-sensing dependent bacterial infection by an N-acyl homoserine lactonase. Nature 411:813-817.

Fray, R. G. 2002. Altering plant-microbe interactions through artificially manipulating bacterial quorum sensing. Ann. Bot. 89:245-253.

Fry, S. M., and Milholland, R. D. 1990a. Multiplication and translocation of Xylella fastidiosa in petioles and stems of grapevines resistant, tolerant and susceptible to Pierce's disease. Phytopathology 80:61-65.

Fry, S. M., and Milholland., R. D. 1990b. Response of resistant, tolerant, and susceptible grapevine tissues to invasion by the Pierce's disease bacterium Xylella fastidosa. Phytopathology 80:66-69.

He, Y.-W., and Zhang, L.-H. 2008. Quorum sensing and virulence regulation in Xanthomonas campestris. FEMS (Fed. Eur. Microbiol. Soc.) Microbiol. Rev. 32:842-857.

Hill, B. L., and Purcell, A. H. 1995. Multiplication and movement of Xylella fastidiosa within grapevine and four other plants. Phytopathology 85:1368-1372.

Hopkins, D. L., and Purcell. A. H. 2002. Xylella fastidiosa: Cause of Pierce's disease of grapevine and other emergent diseases. Plant Dis. 86:1056-1066.
Ionescu, M., Baccari, C., Da Silva, A. M., Garcia, A., Yokota, K., and Lindow, S. E. The XfDSF synthase RpfF of Xylella fastidiosa is a multifunctional protein also required for response to XfDSF. J. Bacteriol. 195:5273-5284.

King, E. O., Ward, M. K., and Raney, D. E., 1954. Two simple media for the demonstration of pyocyanin and fluorescein. J. Lab. Clin. Med. 44:310-317.

Koo, A. J. K., Fulda, M., Browse, J., and Ohlrogge, J. B. 2005. Identification of a plastid acyl-acyl carrier protein synthetase in Arabidopsis and its role in the activation and elongation of exogenous fatty acids. Plant J. 44:620-632.

Mae, A., Montesano, M., Koiv. V., and Palva, E. T. 2001. Transgenic plants producing the bacterial pheromone $\mathrm{N}$-acyl homoserine lactone exhibit enhanced resistance to the bacterial phytopathogen Erwinia carotovora. Mol. Plant-Microbe Interact. 14:1035-1042.

Newman, K. L., Almeida, R. P. P., Purcell, A. H., and Lindow, S. E. 2003. Use of a green fluorescent strain for analysis of colonization of Vitis vinifera by Xylella fastidiosa. Appl. Environ. Microbiol. 69:73197327.

Newman, K. L., Almeida, R. P. P., Purcell, A. H., and Lindow, S. E. 2004 Cell-cell signaling controls Xylella fastidiosa interactions with both insects and plants. Proc. Natl. Acad. Sci. U.S.A. 101:147-152.

Ohlrogge. J. B., and Jaworski, J. G. 1997. Regulation of fatty acid synthesis. Annu. Rev. Plant Physiol. Plant Mol. Biol. 48:109-136.

Purcell, A. H., and Hopkins, D. L. 1996. Fastidious xylem-limited bacterial plant pathogens. Annu. Rev. Phytopathol. 34:131-151.

Ryan, R. P., and Dow, J. M. 2011. Communication with a growing family of diffusible signal factor (DSF) signaling in bacteria. Trends Microbiol. 19:145-152

Sun, Q., Sun, Y., Walker, M. A., and Labavitch, J. M. 2013. Vascular occlusions in grapevines with Pierce's disease make disease symptoms worse. Plant Physiol. 161:1529-1541.

Toth, I. K., Newton, J. A., Hyman, L. J., Lees, A. K., Daykin, M., Ortori, C., Williams, P., and Fray, R. G. 2004. Potato plants genetically modified to produce $\mathrm{N}$-acylhomoserine lactones increase susceptibility to soft rot Erwiniae. Mol. Plant-Microbe Interact. 17:880-887.

Wang, N., Li, J.-L., and Lindow, S. E. 2012. RpfF-dependent regulon of Xylella fastidiosa. Phytopathology 102:1045-1053. 